\title{
Design and Synthesis of Broad Spectrum Trypanosomatid Selective Inhibitors
}

Andrew L. Fraser, Stefanie K. Menzies, Elizabeth F. B. King, Lindsay B. Tulloch, Eoin R. Gould, Marija K. Zacharova, Terry K. Smith* and Gordon J. Florence*.

EaStChem School of Chemistry and School of Biology, Biomedical Sciences Research Complex, University of St Andrews, North Haugh, St Andrews, KY16 9ST, United Kingdom

*Corresponding Authors:

Gordon. J. Florence (gjf1@st-andrews.ac.uk)

Tel: $+44(0) 1334463834$

Fax: +44 (0) 1334463808

http://orcid.org/0000-0001-9921-4399

Terry K. Smith (tks1@st-andrews.ac.uk)

Tel: +44 (0)1334 463412

Fax: +44 (0)1334 463808

http://orcid.org/0000-0003-1994-2009 
Neglected tropical diseases caused by parasitic infections are an ongoing and increasing concern that have a devastating effect on the developing world due to their burden on human and animal health. In this work, we detail the preparation of a focused library of substituted-tetrahydropyran derivatives and their evaluation as selective chemical tools for trypanosomatid inhibition and the follow-on development of photo-affinity probes capable of labeling target protein(s) in vitro. Several of these functionalised compounds maintain low micromolar activity against Trypanosoma brucei, Trypanosoma cruzi, Leishmania major and Leishmania donovani. In addition we demonstrate the utility of the photo-affinity probes for target identification through preliminary cellular localisation studies.

\section{KEYWORDS}

Trypanosomatid, Natural Products, Drug Design, Chemical Tools, Photo-affinity 
Trypanosomatids are a family of parasites which cause life threatening, debilitating disease in humans. ${ }^{1}$ The three major parasitic forms Trypanosoma brucei, Trypanosoma cruzi and Leishmania spp. are the causative agents of African sleeping sickness, Chagas disease and Leishmaniasis respectively. ${ }^{2,3,4}$ Combined, these parasites are responsible for a huge global health burden for millions of people in the worlds poorest countries. Unfortunately, the current treatment options are generally antiquated and many exhibit toxic side effects whilst being largely ineffective. ${ }^{5,6}$ Perhaps more significantly there are very few well-documented drug targets for these diseases. ${ }^{7,8,9}$

The use of natural products in traditional medicinal practices dates back thousands of years and today natural products remain at the forefront of pharmaceutical discovery. ${ }^{10}$ While the structural diversity of natural products is remarkable, they frequently contain significant stereochemical complexity and a high degree of saturation (low $\mathrm{Fsp}^{3}$ count) - properties which are not well reflected in modern HTS screening libraries. ${ }^{10 b}$ Annonaceous acetogenins are a series of fatty acid-derived natural products that have attracted interest as potential anti-cancer agents via their known inhibition of mitochondrial Complex I. ${ }^{11,12}$ Despite the common use of acetogenincontaining Annonaceae plant extracts as traditional medicines in trypanosomatid affected areas, ${ }^{13}$ acetogenins have only been tentatively explored as potential anti-parasitic agents, with initial promising results in several kinetoplastid cell lines. ${ }^{14,15}$

Chamuvarinin (1, Figure 1), an acetogenin first synthesised by our group in 2011, was found to exhibit low micromolar activity towards bloodstream $T$. brucei..$^{16,17}$ Using the chamuvarinin framework as a template, we designed chiral building blocks that mimic key structural features of chamuvarinin (stereochemical complexity, high degree of saturation) and can be rapidly combined to generate simplified non-natural analogues such as $\mathbf{2}$, incorporating a 1,4-triazole 
heterocyclic motif as a mimic of the central cis-substituted tetrahydrofuran moiety in chamuvarinin (Figure 1). These simplified structural analogues maintained anti-parasitic activity with increased, though modest, selectivity compared to mammalian cells. ${ }^{18}$ Herein, we detail further optimization of lead compound 2 using new tetrahydropyran building blocks with substitution on the flanking tetrahydropyran ring systems, as in $3 .{ }^{19}$ We also report extended phenotypic screening of the related kinetoplastids T. cruzi, L. major and L. donovani. ${ }^{20}$ Furthermore, as part of efforts to identify the protein target and establish the mode of action, we have adapted our core inhibitor scaffold to incorporate both a photo-reactive diazirine unit and an orthogonal reporter alkyne tag to produce photo-affinity labelling inhibitors. ${ }^{21}$ Direct incorporation of a small photo-affinity label was viewed as advantageous in terms of minimising disruption of ligand-protein binding interactions in vitro, and reducing non-specific labelling by retaining the structural features identified by phenotypic screening, thereby increasing the likelihood of successful target protein labelling..$^{18}$ 


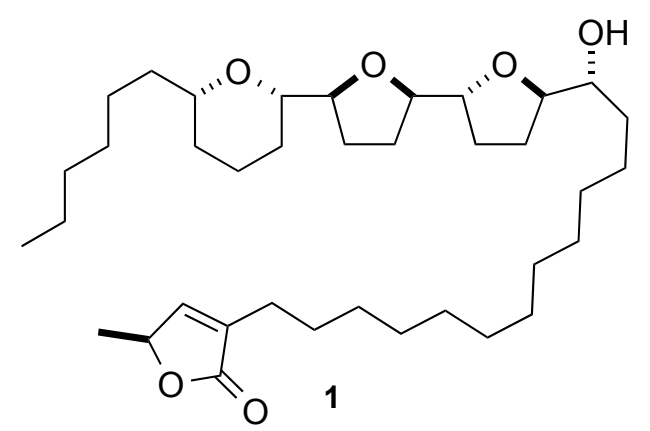

(+)-Chamuvarinin

T. brucei $\mathrm{EC}_{50} 1.4 \mu \mathrm{M}^{6}$

HeLa $E_{50} 2.9 \mu M^{6}$

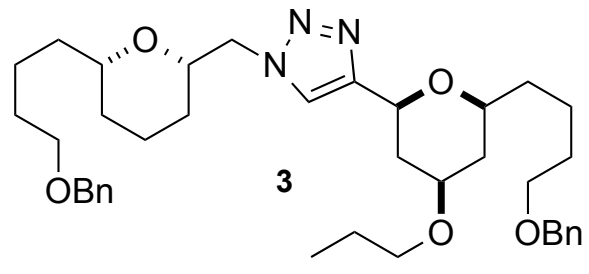

T. brucei $\mathrm{EC}_{50} 7.4 \mu \mathrm{M}$

T. cruzi EC $5017.5 \mu \mathrm{M}$

L. major $\mathrm{EC}_{50} 40.6 \mu \mathrm{M}$

HeLa EC $E_{50}>500 \mu \mathrm{M}$

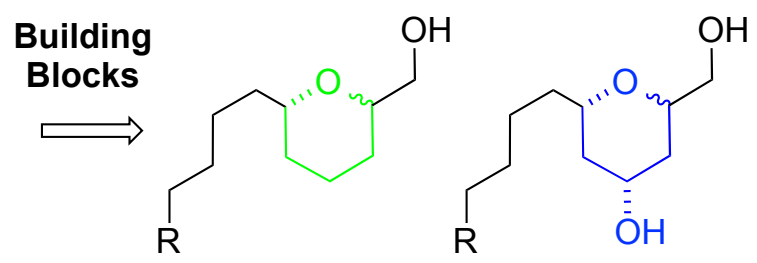

$\sqrt[\begin{array}{c}\text { Simplified } \\ \text { analogues }\end{array}]{ }$

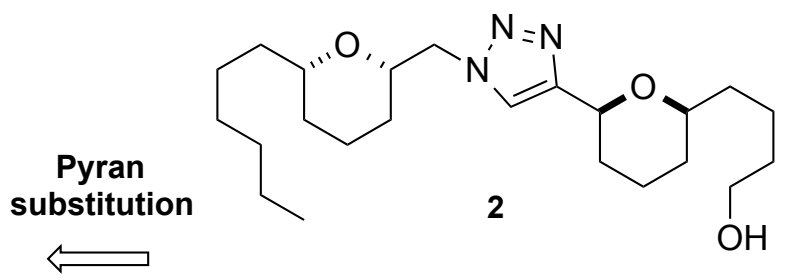

T. brucei $\mathrm{EC}_{50} 1.8 \mu \mathrm{M}$

T. cruzi $\mathrm{EC}_{50} 19.7 \mu \mathrm{M}$

L. major $\mathrm{EC}_{50} 11.8 \mu \mathrm{M}$

HeLa $\mathrm{EC}_{50} 7.0 \mu \mathrm{M}$

Figure 1. Chamuvarinin and simplified analogues

\section{RESULTS AND DISCUSSION}

Synthesis of Functionalised Inhibitors. Our original triazole-based inhibitors were limited as lead compounds due to the limited scope for substitution, preventing further exploration of structure-activity relationships and probing of three-dimensional fragment space. ${ }^{18}$ In order to expand the number of strategic attachment/diversification points we viewed that additional chemical handles could be incorporated on either of the tetrahydropyran (THP) ring systems. In particular modification of the 4-position in the tetrahydropyran rings was attractive as these two sites are directed spatially away from the central tri-heterocyclic core that is most likely to be involved in crucial inhibitor-protein binding interactions (Figure 2). 

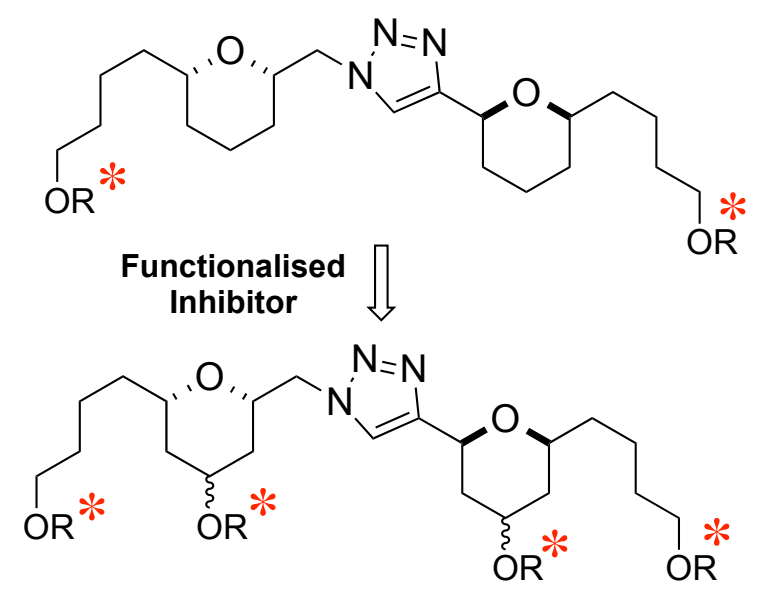

* = Possible functionalisation points

Figure 2. Functionalisation points on original inhibitors compared to new inhibitors

Access to substituted building block 7 was established by application of a Jacobsen heteroDiels-Alder reaction with excellent diastereo- and enantioselectivity (Scheme 1). ${ }^{22}$ This intermediate was key to the synthesis of a series of substituted THP building blocks. Alcohol functionality was installed by reduction with $\mathrm{NaBH}_{4}$ to give equatorial alcohol $\mathbf{8}$ with high diastereocontrol. $^{23}$ TIPS protection, followed by selective TBS deprotection gave alcohol $\mathbf{9}$, which could be independently elaborated to the azide $\mathbf{1 0}$ under Mitsunobu condition or to alkyne 11 by Swern oxidation and Ohira-Bestmann homologation. ${ }^{24,25,26}$ To install the desired triazole heterocycle the $\mathrm{Cu}(\mathrm{I})$-mediated Huisgen cycloaddition was utilized with combinations of suitable azide and alkyne fragments followed by fluoride deprotection to rapidly access $\mathbf{1 3}$ and $\mathbf{1 5}$, respectively, in excellent overall yields. ${ }^{27}$ 


\section{Scheme 1. Synthesis of inhibitors 13 and 15}
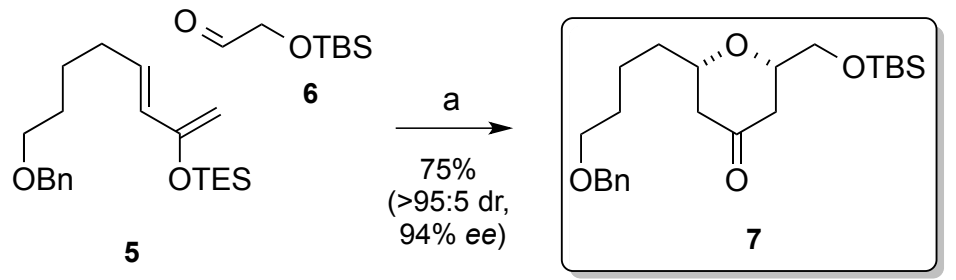

$\underset{\substack{66 \% \\(>95: 5 \mathrm{dr})}}{\mathrm{b}} \overbrace{\mathbf{O}}$

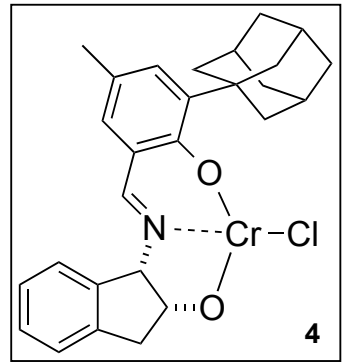

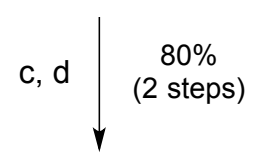

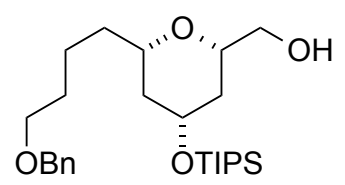

9<smiles>NCC1CCC[C@@H](CCCCOCc2ccccc2)O1</smiles>

$12^{\mathrm{a}}$

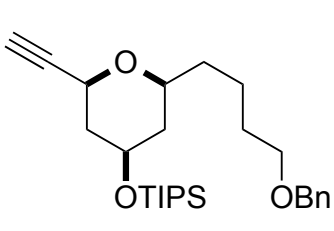

11

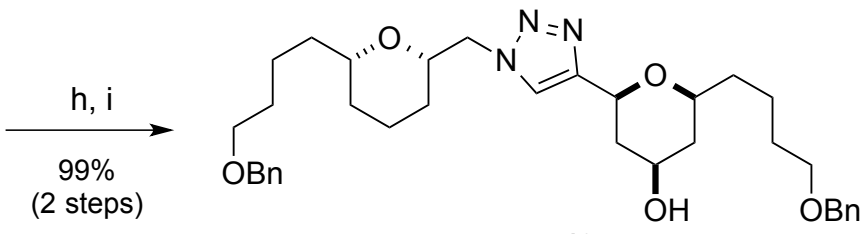

13<smiles>NC[C@H]1C[C@@H](O[SnH3])C[C@H](CCCCOCc2ccccc2)O1</smiles>

10<smiles>C#CC1CCCC(CCCCOCc2ccccc2)O1</smiles>

$14^{\mathrm{a}}$

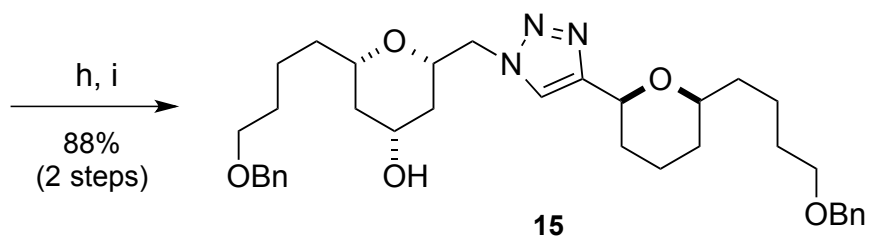

Reagents and conditions: a) $\mathrm{Cr}(\mathrm{III})$ cat. 4, $4 \AA \mathrm{MS}, \mathrm{MTBE}, 0{ }^{\circ} \mathrm{C}-\mathrm{rt}, 24 \mathrm{~h}$, then acidified $\mathrm{CHCl}_{3}$, $\left.20 \mathrm{~min}, \mathrm{~b}) \mathrm{NaBH}_{4}, \mathrm{MeOH}, 0^{\circ} \mathrm{C}, 2 \mathrm{~h}, \mathrm{c}\right)$ TIPS-triflate, 2,6-lutidine, $\left.\mathrm{CH}_{2} \mathrm{Cl}_{2},-78{ }^{\circ} \mathrm{C}, 4 \mathrm{~h}, \mathrm{~d}\right) \mathrm{CSA}$, $\left.\mathrm{CH}_{2} \mathrm{Cl}_{2}, \mathrm{MeOH}, 0{ }^{\circ} \mathrm{C}, 4 \mathrm{~h}, \mathrm{e}\right) \mathrm{PPh}_{3}$, DIPEA, DIAD, DPPA, $\left.0{ }^{\circ} \mathrm{C}-\mathrm{rt}, 16 \mathrm{~h}, \mathrm{f}\right)(\mathrm{COCl})_{2}, \mathrm{DMSO}$, $\mathrm{Et}_{3} \mathrm{~N}, \mathrm{CH}_{2} \mathrm{Cl}_{2},-78{ }^{\circ} \mathrm{C}-\mathrm{rt}, 2 \mathrm{~h}, \mathrm{~g}$ ) dimethyl diazo-2-oxopropylphosphonate, $\mathrm{K}_{2} \mathrm{CO}_{3}, \mathrm{MeOH} / \mathrm{THF}$, $21 \mathrm{~h}, \mathrm{~h}) \mathrm{CuSO}_{4} .5 \mathrm{H}_{2} \mathrm{O}$, sodium ascorbate, $\left.t \mathrm{BuOH}, \mathrm{H}_{2} \mathrm{O}, 20 \mathrm{~h}, \mathrm{i}\right) \mathrm{TBAF}, \mathrm{THF}, 0^{\circ} \mathrm{C}-\mathrm{rt}, 2 \mathrm{~h}$.

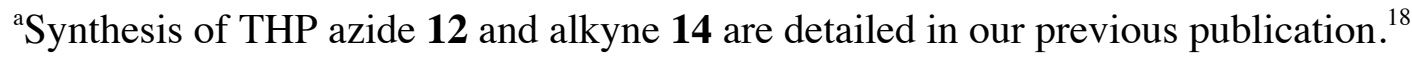


With these modified inhibitor scaffolds in hand, a range of alkyl ethers were prepared (Scheme 2) in order to probe the tolerance for substitution on individual THP rings whilst maintaining anti-parasitic activity. Williamson etherification of $\mathbf{1 3}$ with the specified alkyl halides $(\mathrm{NaH}$, THF) proceeded smoothly to provide ether derivatives $(\mathbf{3}$ and $\mathbf{1 6}-\mathbf{2 6})$.

\section{Scheme 2. Synthesis of alkylated derivatives}

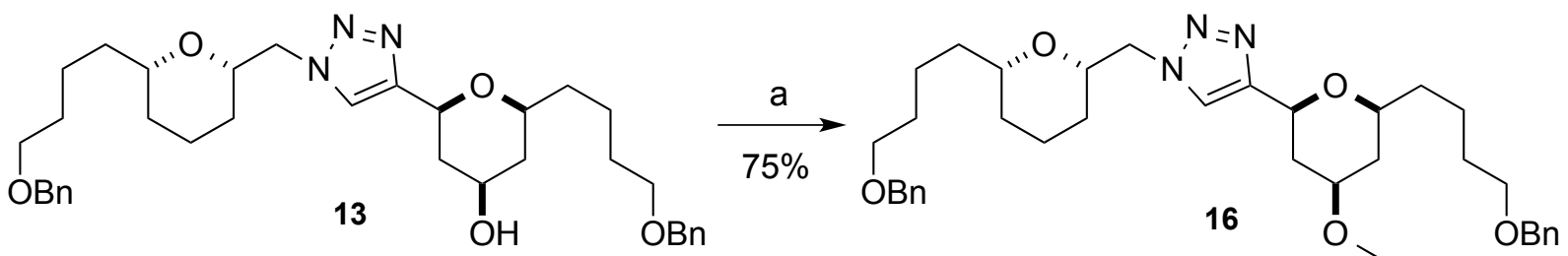

Representive synthesis of substituted inhibitors
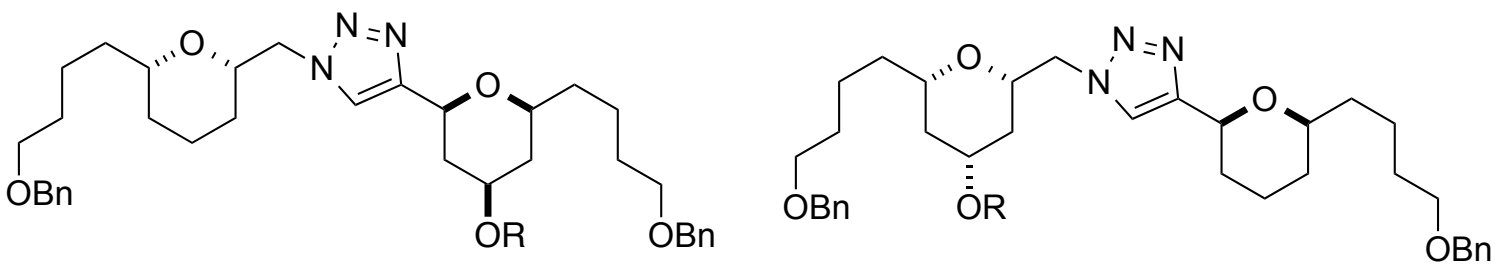
16: $R=M e, 75 \%$
17: $\mathrm{R}=\mathrm{Et}, 76 \%$
18: $\mathrm{R}=n \mathrm{Bu}, 82 \%$
19: $R=B n, 46 \% b$
21: $R=M e, 72 \%$
24: $\mathrm{R}=n \mathrm{Bu}, 67 \%$
3: $\mathrm{R}=n \operatorname{Pr}, 68 \%$
20: $\mathrm{R}=n$ Oct, $74 \%$
22: $\mathrm{R}=\mathrm{Et}, 86 \%$
25: $\mathrm{R}=\mathrm{Bn}, 78 \%{ }^{\mathrm{b}}$
23: $\mathrm{R}=n \mathrm{Pr}, 33 \%$
26: $\mathrm{R}=n$ Oct, $74 \%$

Reagents and conditions: a) NaH, RI, THF, $0{ }^{\circ} \mathrm{C}-$ reflux, $24-48$ h. Note: Reaction time varied

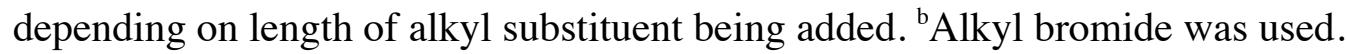

Biological Screening. Following the synthesis of 3, 16-26 we screened against our selected parasite cell lines: T. brucei (bloodstream and procyclic form), T. cruzi (epimastigotes) and $L$. major (promastigotes) in the first instance and counter-screened against the mammalian cell lines HeLa and Vero (Table 1). Addition of a substituent on the alkyne THP ring was well tolerated with alcohol 13 having no loss of potency across all cell lines when compared to the activity of the parent compound $\mathbf{2 7}$ and only a small decrease from our previously reported lead compound 
2. ${ }^{8}$ Results for the analogous alcohol $\mathbf{1 5}$ (with the alcohol on the azide side) were very similar to that of $\mathbf{1 3}$ and this proved to be a general result for this series of compounds with inhibition largely independent of which ring the substituent was located on.

However, the length of the alkyl substituent had a dramatic effect on the type of activity displayed. In bloodstream T. brucei the length of the alkyl substituent had a minimal effect on potency, an $n$-butyl substituent (18) maintained activity when compared to 27. Inhibition activity is only moderately reduced with a bulky $n$-octyl substituent (20). The potency in other parasitic cell lines (insect forms of T. brucei, T. cruzi and L. major) were more sensitive to alkyl ether chain length. However, all tolerated an $n$-propyl ether $(\mathbf{3})$ with potency being maintained in both T. brucei (procyclic) and T. cruzi (epimastigote) with only a small decrease observed in L. major (promastigote), when compared to 27. Interestingly, while inhibition activity in mammalian HeLa cells was unaffected by an ethyl substituent (17), both the $n$-propyl and $n$-butyl substituted variants (3 and 18) had no effect at doses of $500 \mu \mathrm{M}$. Importantly, this means 3 selectively targeted all trypanosomatid cell lines tested with no detrimental activity towards mammalian HeLa cells. Additionally, this series of compounds were evaluated in the mammalian Vero cell line to gauge their activity in non-cancerous cells. This assay demonstrated an even more pronounced effect on cell inhibition activity than that seen for HeLa. The methyl ether variant (16) displayed decreased inhibition activity, while the ethyl ether variant $\mathbf{1 7}$ had no effect at 500 $\mu \mathrm{M}$. An anomalous result was found with compound $\mathbf{2 4}$ having an inhibitory effect on Vero cells. However, it should be noted that the assay indicated an inhibitory effect on respiration, yet the cells were visibly still viable at the highest concentration tested $(>500 \mu \mathrm{M})$, suggesting static rather than cidal activity. 


\section{Table 1. Biological profiles for substituted inhibitors}

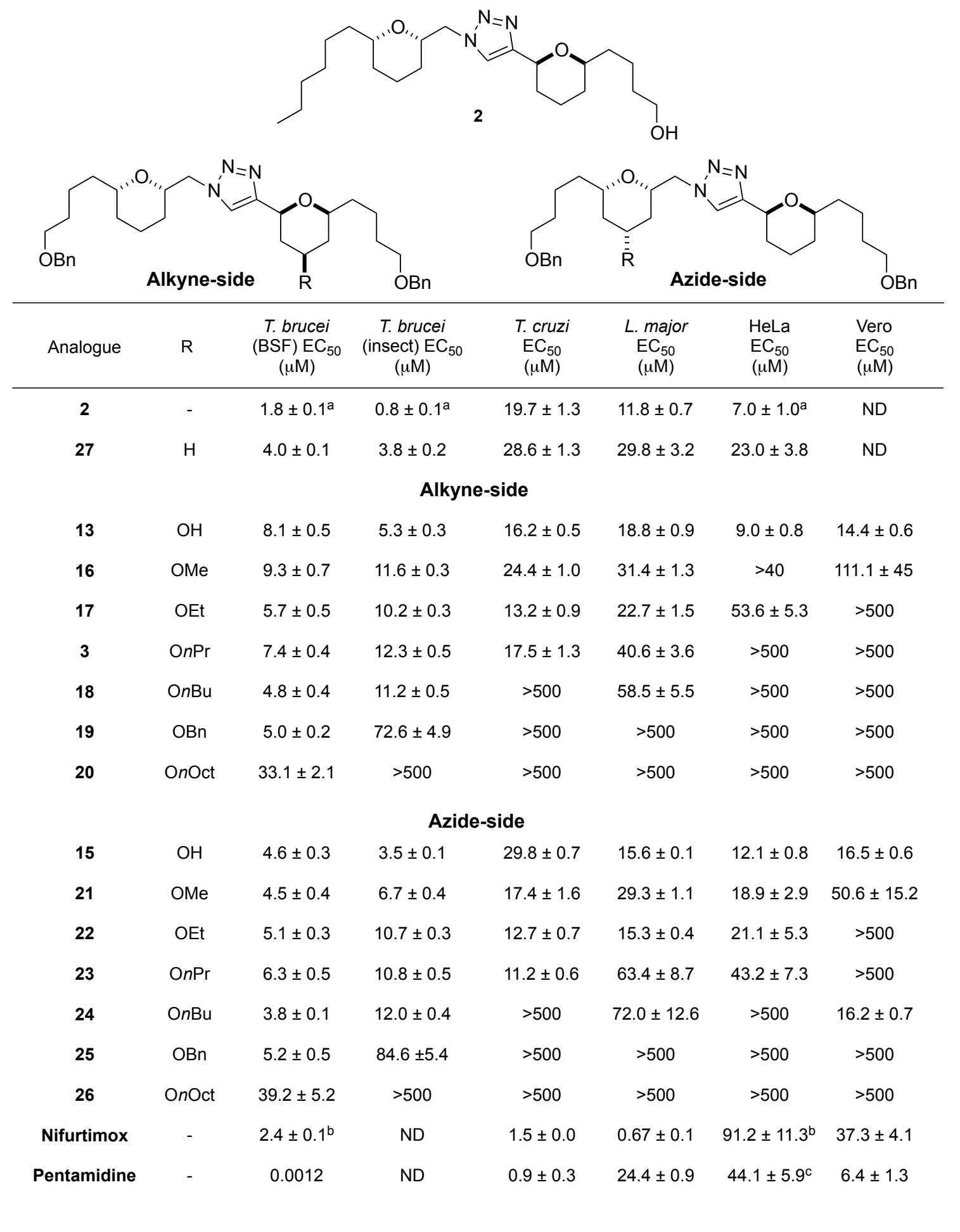

a) $\mathrm{EC}_{50}$ values were determined against bloodstream (BSF) and procyclic (insect) T. brucei brucei, $T$. cruzi (epimastigotes), L. major (promastigotes), mammalian HeLa cells and mammalian Vero cells. Data represents the mean \pm SD of $n=3$ independent experiments performed in triplicate. $\mathbf{2}$ and $\mathbf{2 7}$ shown for comparison. For synthesis of

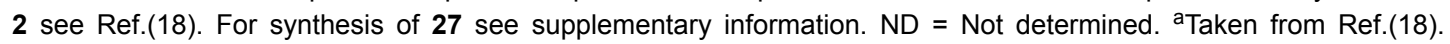

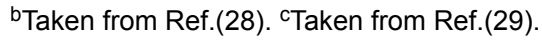


With these promising results, we evaluated selected compounds in the clinically relevant, intracellular forms of $T$. cruzi and $L$. donovani cultured in mammalian THP-1 cells (results for these compounds with bloodstream $T$. brucei are also included, Table 2). Interestingly, intracellular amastigote $T$. cruzi (AMA) were more sensitive to the alkyl ether substituent than the free swimming epimastigote form, with compounds $\mathbf{2 1}$ and $\mathbf{2 2}$ displaying good anti-parasitic activity, while compounds $\mathbf{3}, \mathbf{1 7}$ and $\mathbf{2 3}$ showed no inhibitory effect. By contrast, the alkyl ether substituent appeared to have negligible influence on intracellular L.donovani amastigote (INMAC AMA), with all compounds screened having low to moderate micromolar inhibitory activity, compound 21 being particularly potent. Counter-screening against the host THP-1 mammalian cell line showed that compounds with an alkyl substituent had moderate to no observable inhibitory activity - however the SAR of this effect does not hold a clear trend.

The lack of inhibitory activity in THP-1 cells gave rise to selective compounds towards bloodstream T. brucei, in particular compounds $\mathbf{2 1}$ and $\mathbf{2 3}$ were highly selective when compared to host THP-1 cells (>56 and >79 fold, respectively). The same compounds were also highly selective towards L. donovani. When considering selectivity towards intracellular T. cruzi, only 21 displayed good selectivity compared to the host THP-1 cells ( $>9$ fold). Importantly many of these compounds also had limited inhibitory activity in Vero/HeLa cells (see Table 1), which is significant when considering overall general toxicity towards the host organism. In sum, these results demonstrated that alkyl ether substitution of the THP scaffold was valuable as a method to increase selectivity while maintaining anti-parasitic activity. We have now generated a series of selective chemical tools, with structures of type 21-23 being, in particular, useful in guiding future inhibitor design and development due to their promising activity and selectivity profiles towards the clinically relevant parasite forms. 
Table 2. Biological profiles for selected inhibitors against clinically relevant forms

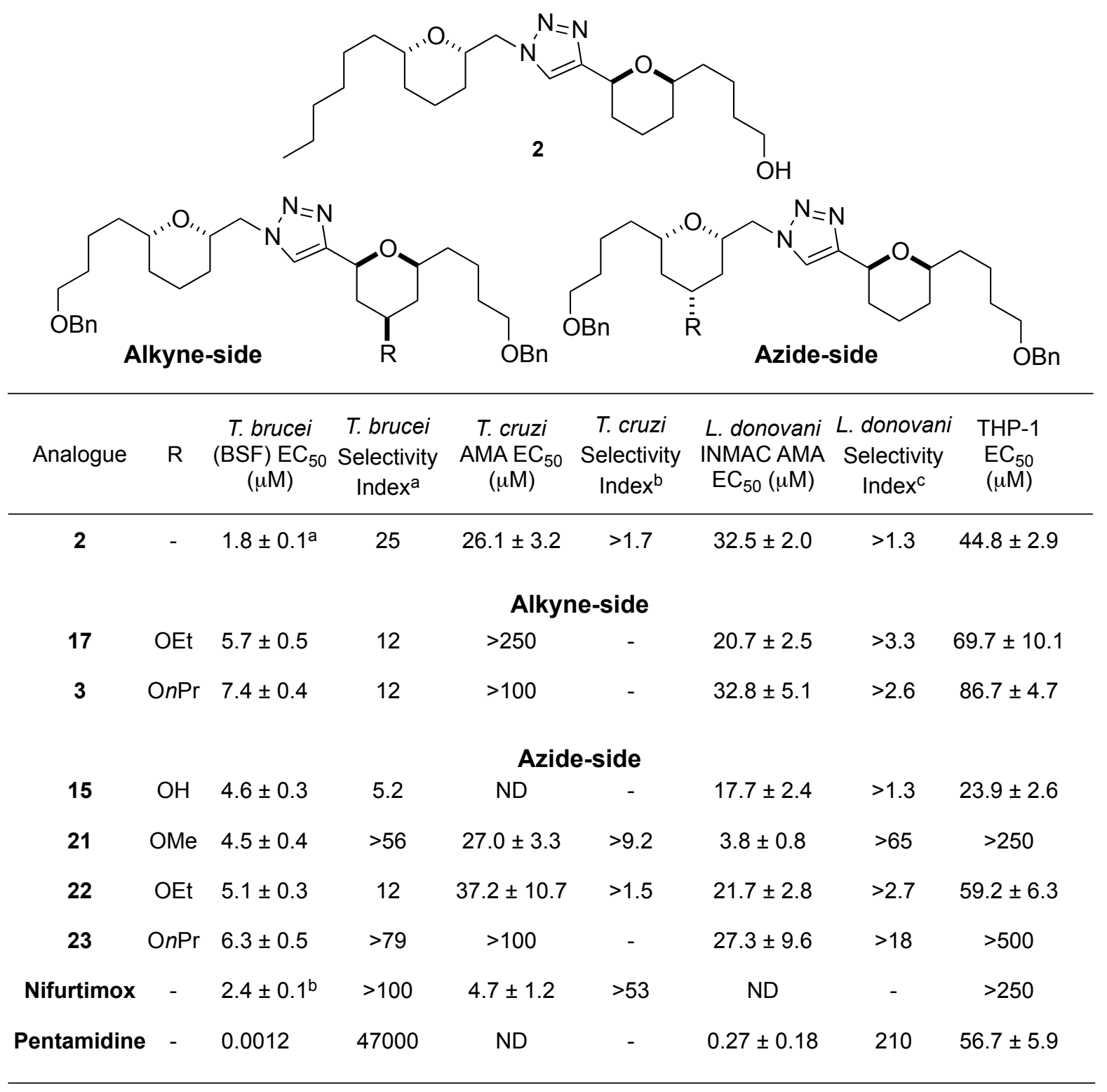

a) $\mathrm{EC}_{50}$ values were determined against mammalian THP-1 cells, T. brucei (BSF), amastigote T. cruzi (AMA) in host mammalian THP-1 cells, L. donovani (promastigote) and L. donovani (AMA INMAC) in host THP-1 cells. Data represents the mean $\pm S D$ of $n=3$ independent experiments performed in triplicate. ${ }^{\text {TT }}$ The selectivity index refers to the $\mathrm{EC}_{50}$ values of $T$. brucei (BSF) compared to mammalian THP-1 cells. ${ }^{\mathrm{b}} \mathrm{The}$ selectivity index refers to the $\mathrm{EC}_{50}$ values of $T$. cruzi (AMA) compared to mammalian THP-1 cells. ${ }^{\mathrm{C}}$ The selectivity index refers to the $\mathrm{EC}_{50}$ values of $L$. donovani (AMA INMAC) compared to mammalian THP-1 cells. 
Synthesis of Photo-Affinity Labelling Probes. With lead analogues against our three kinetoplastid cell lines, we have initiated investigations into the mode of action of our natural product-like inhibitors, particularly the development of suitable photo-affinity labelling probes for protein target elucidation. Our SAR studies showed parasite inhibition was sensitive to increasing sterics on the core THP scaffolds, particularly in T. cruzi and L. major. Thus, when considering established methods ${ }^{30}$ to incorporate photo-reactive tags we were concerned by the additional steric demands and the resultant structural deviation causing a loss of affinity and/or selectivity for relevant protein targets. In an effort to minimise such structural changes, compound $\mathbf{3 1}$ was targeted with the appropriate diazirine and alkyne groups incorporated directly onto the inhibitor backbone (Scheme 3).

Following significant route optimisation it was found that initial deprotection of silyl ether $\mathbf{2 8}^{31}$ with TBAF was preferential prior to the installation of the diazirine unit. With the free alcohol 29 in hand, installation of the diazirine group could be effected in a one-pot synthesis utilising a modified literature procedure. ${ }^{32}$ Treatment with liquid ammonia in a sealed tube at elevated temperature was necessary to form the imine, which after addition of hydroxylamine sulfonic acid yielded the intermediate diaziridine. Subsequent oxidation using molecular iodine gave the desired diazirine compound $\mathbf{3 0}$ in good yield. Mild conditions for installation of the alkyne chemical handle were sought due to the temperature sensitivity of the diazirine group. Optimal conditions involved sequential Swern oxidation followed by Pinnick oxidation to the carboxylic acid. ${ }^{25,33}$ Alkyne functionality was installed using simple amide coupling with propargyl amine to deliver the desired photo-affinity labelling probe 31. The azide-side photo-affinity labelling inhibitor 32 was synthesised in an analogous manner. ${ }^{31}$ 


\section{Scheme 3. Synthesis of photo-affinity labelling probe 31}

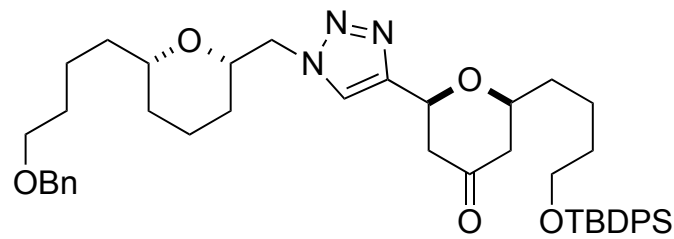

28

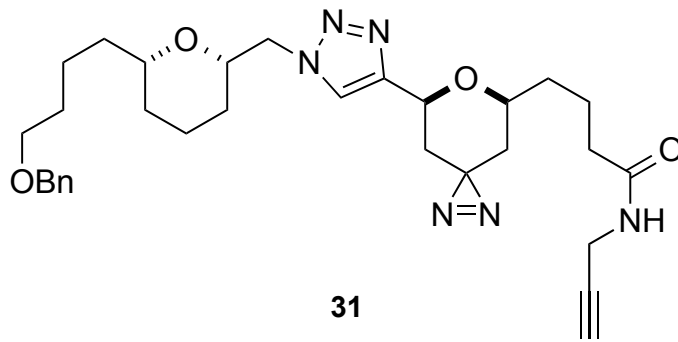

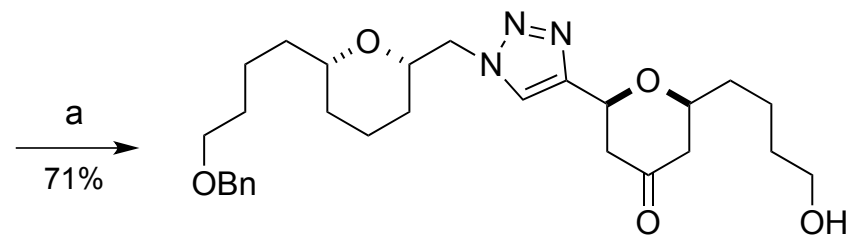

29
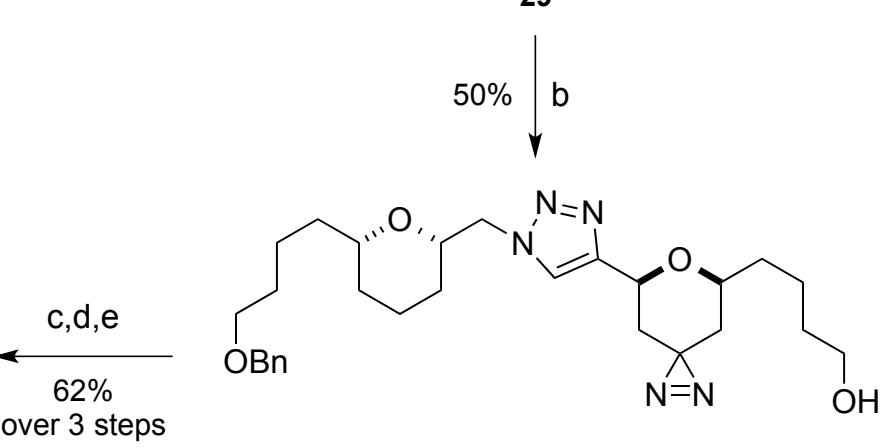

30

Reagents and conditions: a) TBAF, THF, $\left.0{ }^{\circ} \mathrm{C}-\mathrm{rt}, 2 \mathrm{~h}, \mathrm{~b}\right) \mathrm{NH}_{3}(\mathrm{l}), 80{ }^{\circ} \mathrm{C}, 3 \mathrm{~h}$, then $\mathrm{H}_{2} \mathrm{NOSO}_{3} \mathrm{H}$, $18 \mathrm{~h}$, then $\left.\left.\mathrm{I}_{2}, \mathrm{MeOH}, \mathrm{c}\right)(\mathrm{COCl})_{2}, \mathrm{DMSO}, \mathrm{Et}_{3} \mathrm{~N}, \mathrm{CH}_{2} \mathrm{Cl}_{2},-78^{\circ} \mathrm{C}-\mathrm{rt}, 2 \mathrm{~h}, \mathrm{~d}\right) \mathrm{NaClO}_{2}$, $\left.\mathrm{NaH}_{2} \mathrm{PO}_{4} .2 \mathrm{H}_{2} \mathrm{O}, t \mathrm{BuOH}, \mathrm{H}_{2} \mathrm{O}, 0^{\circ} \mathrm{C}-\mathrm{rt}, 1.5 \mathrm{~h}, \mathrm{e}\right)$ Propargylamine, EDCI.HCl, DMAP, $\mathrm{CH}_{2} \mathrm{Cl}_{2}$, $18 \mathrm{~h}$

As detailed in Table 3, the diazirine containing probes were assessed for trypanocidal activity in T. brucei, T. cruzi and L. major. Pleasingly diazirine analogues $\mathbf{3 0}$ and $\mathbf{3 2}$ maintain good inhibition profiles, while $\mathbf{3 1}$ and $\mathbf{3 3}$ incorporating the alkyne reporter also maintains good levels of inhibition in all parasitic cell lines with the exception of $T$. cruzi which displayed reduced levels of inhibition. Photo-affinity probes suitable for interrogation of T. cruzi are currently being sought. The minimal structural differences between these compounds and the substituted ether inhibitors validate our design principles for the apparent continuation of binding to the target protein(s). 
Table 3. Biological profiles for photo-affinity labelling probes

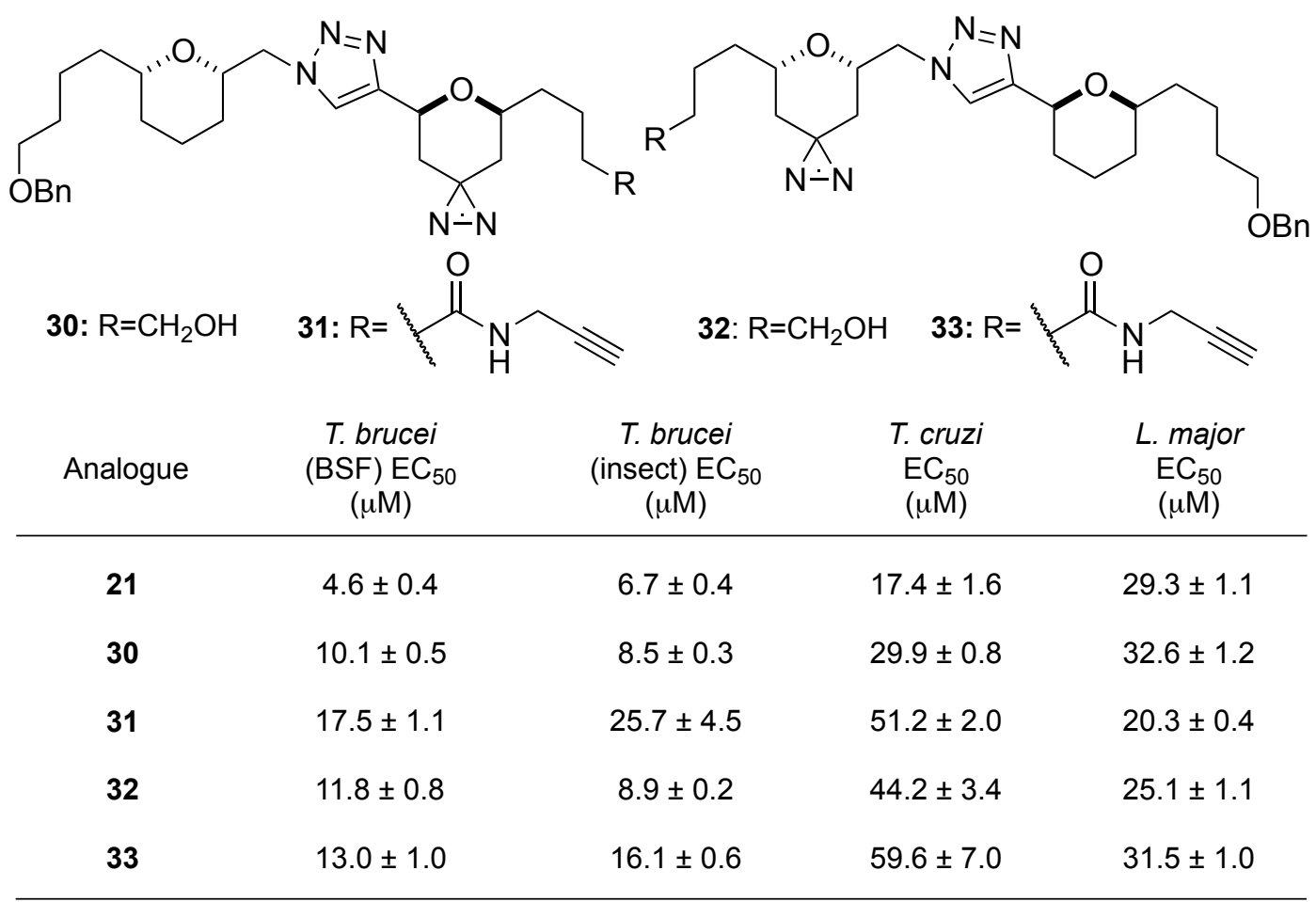

a) $\mathrm{EC}_{50}$ values were determined against bloodstream (BSF) and procyclic (insect) T. brucei brucei, T. cruzi (epimastigotes), L. major (promastigotes). Data represents the mean $\pm \mathrm{SD}$ of $\mathrm{n}=$ 3 independent experiments performed in triplicate.

We finally looked to obtain proof of principle that our photo-affinity labelling derivatives were capable of selective protein binding through cell localisation studies in T. brucei and L. major. Incubation of 31 with L. major was followed by cross-linking with UV irradiation (365 $\mathrm{nm}$ ) to label target protein(s) within the cell. Subsequent cell permeabilisation and 'click' reaction with commercially available Cy5.5 azide fluorescent tag allowed visualization of inhibitor-protein conjugates by fluorescence microscopy (Figure 3a). Co-localisation with MitoTracker RedCMXros indicated that inhibitors primarily target the mitochondrion. Similar mitochondrial labelling was obtained with procyclic T. brucei cells and compound 33 (Figure 3b). Control experiments with cells exposed to compound $\mathbf{2}$, lacking the diazirine group and therefore unable 
to UV-crosslink to its target(s), showed no protein labeling, suggesting that the labeling with Cy5.5 reporter is specific to the photo-affinity probe. Further details of the isolation and identification of the mitochondrial target as the $\mathrm{F} 1 \alpha / \mathrm{F} 1 \beta$ subunits of TbATPase (Complex V) in procyclic $T$. brucei using $\mathbf{3 1}$ are detailed elsewhere. ${ }^{34}$ Ongoing studies are underway to establish whether the ATPase is a common target in bloodstream T. brucei, intracellular T. cruzi and Leishmania sp. using $\mathbf{3 1}$ and details will be reported in due course.

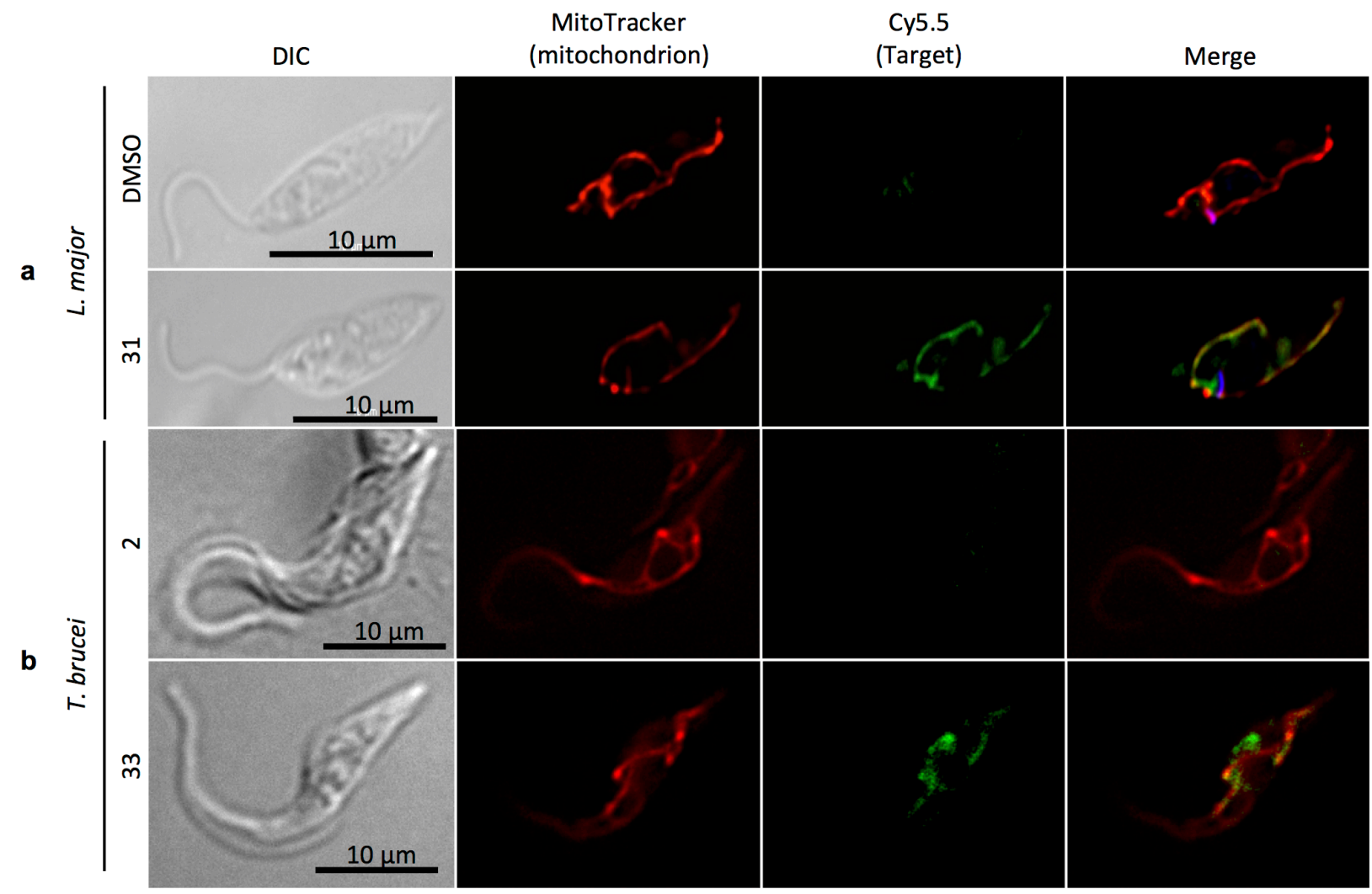

Figure 3. a) Co-localisation between MitoTracker Red CMXros (red) stained L. major cells labelled with compound $\mathbf{3 1}$ and Cy5.5 fluorescent tag (green). DMSO is shown as a negative control, b) Co-localisation between MitoTracker Red CMXros (red) stained procyclic T. brucei cells labelled with compound $\mathbf{3 3}$ and Cy5.5 fluorescent tag (green). Cells exposed to compound 2 (not capable of photo-crosslinking) shown as a negative control. 


\section{CONCLUSION}

Building on our initial natural product based $T$. brucei inhibitors, a novel series of bisterahydropyran compounds were synthesised and screened against a panel of trypanosomatids. Members of this novel class of compound display broad-spectrum kinetoplastid inhibition with minimal toxicity towards several mammalian cell lines. A systematic investigation of alkyl substitution on the tetrahydropyran rings revealed the key steric demands across each cell line, creating a 'window of selectivity' where low micromolar parasite inhibition can be maintained and mammalian cells remain viable. Extension into the clinically relevant forms of T. cruzi and L. major also showed promising activity and selectivity profiles. We have successfully functionalized our chemical probes with dual photo-affinity and reporter capabilities and shown

that they target the mitochondria in both T. brucei and L. major. ${ }^{34}$ Identification and analysis of the mitochondrial protein target in conjunction with further biological validation will now enable further structural simplification and lead optimization in terms of potency and selectivity, with the view to the development of natural product-inspired therapies for trypanosomatid associated diseases.

\section{ASSOCIATED CONTENT}

\section{Supporting Information}

Supporting Information includes details of; i) chemical synthesis and compound characterization; and ii) biological methods, cell cultures, cytotoxic assays and subcellular localization studies. 


\section{ACKNOWLEDGEMENTS}

This work was funded by the Leverhulme Trust (GJF) and the European Community's Seventh Framework Programme under grant agreement No. 602773 [Project KINDRED] (TKS). We thank the EPSRC National Mass Spectrometry Service Centre, Swansea, UK for mass spectrometry services. All authors declare no conflict of interest.

\section{ABBREVIATIONS}

MS, molecular sieves, TIPS triisopropylsilyl, CSA, ( \pm )-camphorsulfonic acid, DIPEA, N,Ndiisopropylethylamine, DIAD, diisopropyl azodicarboxylate, DPPA, diphenyl phosphoryl azide, EDCI.HCl, 1-ethyl-3-(3-dimethylaminopropyl)carbodiimide hydrochloride, RI, alkyl iodide [where $\mathrm{R}=$ respective alkyl substituent], spp., species, TBDPS, tert-butyldiphenylsilyl, dr, diastereomeric ratio, cat., catalyst, SD, standard deviation, BSF, blood stream form, ND, not determined, PBS, phosphate-buffered saline, SDS, sodium dodecyl sulfate, SDS-PAGE, sodium dodecyl sulfate polyacrylamide gel electrophoresis, AMA INMAC, amastigote in macrophages. 


\section{REFERENCES}

(1) Goater, T. M., Goater, C. P., and Esch, G. W. (2014) Parasitism: The diversity and ecology of animal parasites, 2nd ed., Cambridge University Press, Cambridge, UK.

(2) World Health Organization. Trypanosomiasis, human African (sleeping sickness), available online at http://www.who.int/mediacentre/factsheets/fs259/en/ (accessed 15 October, 2017).

(3) World Health Organization. Chagas disease (American trypanosomiasis), available online at http://www.who.int/mediacentre/factsheets/fs340/en/ (accessed 15 October, 2017).

(4) World Health Organization. Leishmaniasis, available online at http://www.who.int/mediacentre/factsheets/fs375/en/ (accessed 15 October, 2017).

(5) Steverding, D. (2010) The Development of Drugs for Treatment of Sleeping Sickness: a Historical Review. Parasit. Vectors. 3, 15, DOI 10.1186/1756-3305-3-15.

(6) Delespaux, V., and de Koning, H. P. (2007) Drugs and drug resistance in African trypanosomiasis. Drug Resistance Updates 10, 30 - 50, DOI 10.1016/j.drup.2007.02.004.

(7) Gilbert, I.H. (2013) Drug Discovery for Neglected Diseases: Molecular Target-Based and Phenotypic Approaches. J. Med. Chem. 56, 7719-26, DOI 10.1021/jm400362b.

(8) Amata, E., Xi, H., Colmenarejo, G., Gonzalez-Diaz, R., Cordon-Obras, C., Berlanga, M., Manzano, P., Erath, J., Roncal, N. E., Lee, P. J., Leed, S. E., Rodriguez, A., Sciotti, R. J., Navarro, M., and Pollastri, M. P. (2016) Identification of "Preferred" Human Kinase Inhibitors for Sleeping Sickness Lead Discovery. Are Some Kinases Better than Others for Inhibitor Repurposing? ACS Infect. Dis. 2, 180-186, DOI 10.1021/acsinfecdis.5b00136.

(9) E. Torreele, B. B. Trunz, D. Tweats, M. Kaiser, R. Brun, G. Mazué, M. A. Bray, and B. Pécoul (2010) Fexinidazole - A New Oral Nitroimidazole Drug Candidate Entering Clinical Development for the Treatment of Sleeping Sickness. PLoS Neg. Trop. Dis. 4, e923, DOI 10.1371/journal.pntd.0000923. 
(10) (a) Newman, D. J. and Cragg, G. M. (2016) Natural Products as Sources of New Drugs from 1981 to 2014 J. Nat. Prod. 79, 629-661, DOI 10.1021/acs.jnatprod.5b01055. (b) Lovering, F. (2013) Escape from Flatland 2: Complexity and Promiscuity. Med. Chem. Commun. 4, 515519, DOI 10.1039/C2MD20347B.

(11) Kojima, N., and Tanaka, T. (2009) Medicinal Chemistry of Annonaceous Acetogenins: Design, Synthesis, and Biological Evaluation of Novel Analogues. Molecules 14, 3621-3661 and references cited therein. DOI 10.3390/molecules14093621.

(12) Bermejo, A., Figadère, B., Zafra-Polo, M.-C., Barrachina, I., Estornellc, E., and Cortes, D. (2005) Acetogenins from Annonaceae: recent progress in isolation, synthesis and mechanisms of action. Nat Prod Rep. 22, 269-303, DOI 10.1039/b500186m.

(13) Ogbadoyi, E. O., Abdulganiy, A. O., Adama, T. Z., and Okogun, J. I. In vivo Trypanocidal Activity of Annona senegalensis Pers. Leaf Extract Against Trypanosoma brucei brucei. (2007) J. Ethnopharmacol. 112, 85 - 89, DOI 10.1016/j.jep.2007.02.015.

(14) Hoet, S., Opperdoes, F., Brun, R., and Quetin-Leclercq, J. (2004) Natural Products Active Against African Trypanosomes: a Step Towards New Drugs. Nat. Prod. Rep. 21, 353-364, DOI $10.1039 / \mathrm{b} 311021 \mathrm{~b}$

(15) Lima, L. A. R. S., Alves, T. M. A., Zani, C. L., Sales Júnior, P. A., Romanha, A. J., Johann, S., Cisalpino, P. S., Pimenta, L. P. S., and Boaventura, M. A. D. (2014) In vitro Cytotoxic, Antifungal, Trypanocidal and Leishmanicidal Activities of Acetogenins Isolated from Annona cornifolia A. St. -Hil. (Annonaceae). An Acad Bras Cienc 86, 829-839, DOI 10.1590/00013765201420130048 .

(16) Florence, G. J., Morris, J. C., Murray, R. G., Osler, J. D., Reddy, V. R., and Smith, T. K. (2011) Synthesis and Stereochemical Assignment of (+)-Chamuvarinin. Org. Lett. 13, 514-517. DOI $10.1021 / 011028699$.

(17) Florence, G. J., Morris, J. C., Murray, R. G., Vanga, R. R., Osler, J. D., and Smith, T. K. (2013) Total Synthesis, Stereochemical Assignment, and Biological Activity of Chamuvarinin and Structural Analogues. Chem. Eur. J. 19, 8309-20, DOI 10.1002/chem.201204527.

(18) Florence, G. J., Fraser, A. L., Gould, E. R., King, E. F. B., Menzies, S. K., Morris, J. C., Tulloch, L. B., and Smith, T. K. (2014) Non-natural Acetogenin Analogues as Potent Trypanosoma brucei Inhibitors. ChemMedChem 9, 2548-2556, DOI 10.1002/cmdc.201402272. 
(19) Florence, G. J., Fraser, A. L., Gould, E. R., King, E. F., Menzies, S. K., Morris, J. C., Thomson, M. I., Tulloch, L. B., Zacharova, M. K., and Smith, T. K. (2016) Development of Simplified Heterocyclic Acetogenin Analogues as Potent and Selective Trypanosoma brucei Inhibitors. ChemMedChem 11, 1503-1506, DOI 10.1002/cmdc.201600210.

(20) Gould, E. R., King, E. F. B., Menzies, S. K., Fraser, A. L., Tulloch, L. B., Zacharova, M. K., Smith, T. K., and Florence, G. J. (2017) Simplifying Nature: Towards the Design of Broad Spectrum Kinetoplastid Inhibitors, Inspired by Acetogenins. Bioorg. Med. Chem. 25, 6126-6136, DOI 10.1016/j.bmc.2017.01.021.

(21) Dubinsky, L., Krom, and B. P., Meijler, M. M. (2012) Diazirine Based Photoaffinity Labeling. Bioorg. Med. Chem. 20, 554-570, DOI 10.1016/j.bmc.2011.06.066.

(22) Dossetter, A. G., Jamison, T. F., and Jacobsen, E. N. (1999) Highly Enantio- and Diastereoselective Hetero-Diels-Alder Reactions Catalyzed by New Chiral Tridentate Chromium (III) Catalysts. Angew. Chem. Int. Ed. 38, 2398-2400, DOI 10.1002 / (SICI) 1521-3757 (19990816) 111: $16<2549$ :: AID-ANGE2549> 3.0.CO; 2-H.

(23) A Mosher's ester analysis of alcohol 7 was used to determine ee and absolute configuration, see Dale, J. A., and Mosher, H. S. (1973) Nuclear Magnetic Resonance Enantiomer Reagents. Configurational Correlations via Nuclear Magnetic Resonance Chemical Shifts of Diastereomeric Mandelate, $O$-Methylmandelate, and $\alpha$-Methoxy- $\alpha$ - trifluoromethylphenylacetate (MTPA) Esters. J. Am. Chem. Soc. 95, 512-519, DOI 10.1021/ja00783a034.

(24) Thompson, A. S., Humphrey, G. R., DeMarco, A. M., Mathre, D. J., and Grabowski, E. J. J. (1993) Direct Conversion of Activated Alcohols to Azides Using Diphenyl Phosphorazidate. A Practical Alternative to Mitsunobu Conditions. J. Org. Chem. 58, 5886-5888, DOI 10.1021/jo00074a008.

(25) Omura, K., and Swern, D. (1978) Oxidation of Alcohols by "Activated" Dimethyl Sulfoxide. A Preparative, Steric and Mechanistic Study. Tetrahedron 34, 1651-1660, DOI 10.1016/0040-4020(78)80197-5.

(26) Roth, G., Liepold, B., Müller, S, and Bestmann, H. (2004) Further Improvements of the Synthesis of Alkynes from Aldehydes. Synthesis, 59-62, DOI 10.1055/s-2003-44346. 
(27) Rostovtsev, V. V., Green, L. G., Fokin, V. V., and Sharpless, K. B. (2002) A Stepwise Huisgen Cycloaddition Process: Copper(I)-Catalyzed Regioselective "Ligation" of Azides and Terminal Alkynes. Angew. Chemie. Int. Ed. 41, 2596-2599, DOI 10.1002/15213773(20020715)41:14<2596::AID-ANIE2596>3.0.CO;2-4.

(28) Zhou, L., Stewart, G., Rideau, E., Westwood, N. J., and Smith, T. K. (2013) A Class of 5Nitro-2-Furancarboxylamides With Potent Trypanocidal Activity Against Trypanosoma brucei in vitro. J. Med. Chem. 56, 796-806, DOI 10.1021/jm301215e.

(29) Wang, X., Fiorini, Z., Smith, C., Zhang, Y., Li, J., Watkins, L. R., and Yin, H. (2012) Repositioning Antimicrobial Agent Pentamidine as a Disruptor of the Lateral Interactions of Transmembrane Domain 5 of EBV Latent Membrane Protein 1. PLoS One 7, e47703, DOI 10.1371/journal.pone.0047703.

(30) Mayer, T., and Maier, M. E. (2007) Design and Synthesis of a Tag-Free Chemical Probe for Photoaffinity Labeling. Eur. J. Org. Chem. 4711-4720, DOI 10.1002/ejoc.200700188.

(31) See Supporting Information for full synthetic details.

(32) Dubinsky, L., Jarosz, L. M., Amara, N., Krief, P., Kravchenko, V. V., Krom, B. P., and Meijler, M. M. (2009) Synthesis and Validation of a Probe to Identify Quorum Sensing Receptors. Chem. Commun., 7378-7380, DOI 10.1039/B917507E.

(33) Bal, B. S., Childers, W. E., and Pinnick, H. W. (1981) Oxidation of $\alpha, \beta$-Unsaturated Aldehydes. Tetrahedron 37, 2091-2096, DOI 10.1016/S0040-4020(01)97963-3.

(34) Tulloch, L. B., Menzies, S. K., Fraser, A. L., Gould, E. R., King, E. F. B., Zacharova, M. K., Florence, G. J., and Smith, T. K. (2017) Photo-Affinity Labelling and Biochemical Analyses Identify the Target of Trypanocidal Simplified Natural Product Analogues. PLoS Negl Trop Dis 11, e0005886, DOI 10.1371/journal.pntd.0005886. 

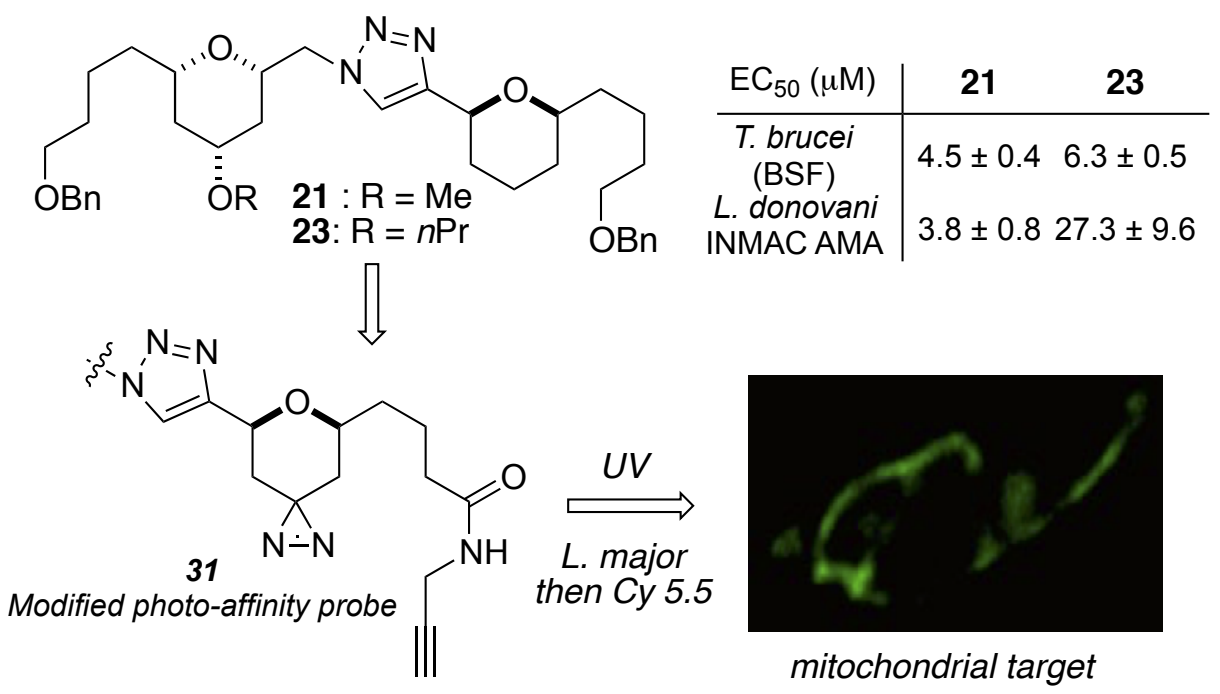